\title{
Metaplastic (hyperplastic) polyps of the large bowel: benign neoplasms after all?
}

What are metaplastic, or as they are now more commonly called, hyperplastic, polyps of the large bowel? Commonest of all colorectal polyps, and frequently having a tantalising epidemiological and anatomical relation with adenomas and carcinomas despite having no significant malignant potential, ${ }^{12}$ the nature and importance of these small focal mucosal excrescences remains an enigma. Metaplastic polyps are composed of elongated crypts showing epithelial hyperplasia in the proliferative zone, increased branching, and a slowing of migration of cells up the crypt. This is thought to lead to hypermaturation towards the luminal surface and the development of the serrated pattern that is their most distinctive histological feature. Abnormal cellular differentiation is manifested by the expression of atypical mucus and structural glycoproteins (including carcinoembryonic antigen) and intracellular enzymes, and decreased secretory component and epithelial $\operatorname{IgA} .^{3}$

Despite the evidence that they are localised abnormalities of crypt cell proliferation and differentiation, pathologists have been very reluctant to consider metaplastic polyps as neoplasms. Reasons for this include the observations that although there is undoubtedly epithelial hyperplasia, the overall organisation of the crypt is maintained, that there seems to be ordered differentiation of the epithelium towards the luminal surface, and, most important of all, that they show no histological features of dysplasia. The fact that similar serrated crypt patterns are occasionally found in association with mucosal ischaemia or chronic inflammation, and that metaplastic polyps express trefoil peptides that are associated with the ulcer associated cell lineage,${ }^{4}$ has led some to suggest that they represent focal responses to mucosal damage. However, convincing histological evidence of such damage in the mucosa surrounding metaplastic polyps is seldom discernible. Moreover, a serrated growth pattern is not unique to non-neoplastic colorectal lesions and may be found in otherwise unequivocally dysplastic lesions, so called serrated adenomas. ${ }^{5}$

The most compelling evidence that metaplastic polyps are truly neoplastic lesions would be the demonstration of cellular clonality and the consistent involvement of somatic genetic lesions of growth control or DNA repair genes. Although little research has been carried out into these aspects of metaplastic polyps, there are occasional reports of single lesions with clonal deletions of chromosome $1 p^{67}$ or with DNA microsatellite instability, ${ }^{78}$ abnormalities that are well recognised in colorectal adenomas and carcinomas. Otori et al (see page 660) describe a molecular pathological study of metaplastic polyps in which they find K-ras mutations in nine $(47 \%)$ of 19 , but no evidence of APC or p53 lesions. Another recent study presented similar findings with K-ras mutations in $22 \%$ (five of 22 ) of polyps. ${ }^{9}$ Collectively, these observations represent a significant challenge to the view that metaplastic polyps are non-neoplastic lesions and although they do not prove conclusively a clonal origin, they strengthen the proposal that these polyps are benign neoplasms rather than hyperplastic lesions of contiguous crypts. Their lack of APC mutations correlates with the absence of dysplasia, ${ }^{9}$ while the chance occurrence of APC mutation within metaplastic polyps is likely to explain the rare development of adenomas within them (so called mixed metaplasticadenomatous polyps). ${ }^{5}$

If metaplastic polyps are true neoplasms resulting from somatic mutation followed by clonal expansion, their epidemiological ${ }^{1}$ and anatomical ${ }^{2}$ association with sporadic colorectal adenomas and carcinomas can be explained by the fact that factors governing mutation frequency would be expected to influence the incidence of both types of tumour. Accumulation of somatic mutations with age would also explain the increasing prevalence of metaplastic polyps in older people. The fundamental difference between metaplastic polyps and adenomas would be that whereas both are neoplasms, it is only adenomas that possess the inherent capacity for malignant progression. Conceivably, the genetic lesion that induces metaplastic polyps merely leads to a re-setting of the normal intracryptal balance between proliferation, differentiation and cell loss to a new steady state level. Although this would be sufficient to result in the typical phenotypic features of the metaplastic polyp, it would not predispose to malignant progression unless the lesion acquired, by chance, some additional mutation, such as in the APC gene, to disrupt this stability. The fact that metaplastic polyps virtually never grow to more than a few millimetres in size would be consistent with this newly acquired steady state.

What, if anything, does the occurrence of K-ras mutations in $22-47 \%$ of metaplastic polyps tell us about their origin? The proportion of affected lesions seems rather low to suggest that this mutation is the fundamental genetic event involved, although the figure of $47 \%$ is similar to the observed frequency of K-ras mutation in adenomas. The colonic lesions that are consistently accompanied by K-ras mutation are so called aberrant crypt foci (ACF), ${ }^{9}$ tiny hyperplastic oligocryptal lesions that can only be visualised with a dissecting microscope or a magnifying colonoscope. Not surprisingly, they are commoner in colons bearing carcinomas. A small minority of these ACFs also harbour APC mutations, ${ }^{9}$ in which case they show histological features of dysplasia and are thought to progress to adenomas. The great majority of ACFs seem to be non-progressive and may eventually regress through apoptosis. ${ }^{10}$ However, some show small epithelial infoldings into the crypt that give rise to a serrated appearance mimicking mini-metaplastic polyps. ${ }^{11}$ A plausible scenario, therefore, is that these lesions have acquired a metaplastic polyp inducing mutation and are destined to evolve into macroscopic metaplastic polyps. This is not to imply that all metaplastic polyps arise from ACFs - the essential mutation could arise in normal epithelium giving rise to metaplastic polyps de novo (which would not have K-ras mutations) - but it seems that the metaplastic polyp 
mutation and mutant $\mathrm{K}$-ras might act synergistically in the development of the established lesion.

What are the implications of metaplastic polyps being true neoplasms for the practising clinician and for strategies for colorectal cancer prevention? Should it alter our approach to the management of patients with such lesions? The answer is a definite 'no'. Even if metaplastic polyps are tumours, there is firm pathological and clinical evidence that they are not lesions with any significant risk of malignant transformation and they can be safely left alone. The only exception is the rare, larger $(>1 \mathrm{~cm})$, often pedunculated lesion that may turn out to be a mixed metaplastic-adenomatous polyp on histological examination. What about multiple metaplastic polyps? It could be argued that these are indicative of increased intracolonic mutational activity and that affected patients are at increased risk of colorectal cancer, warranting close follow up. While this may be true for younger patients with large numbers of metaplastic polyps (so called metaplastic polyposis), ${ }^{12}$ findings from prospective studies indicate that older people with just a few lesions have no increased risk of colorectal adenomas or carcinomas over five years compared with unaffected people. ${ }^{13}$ If a gene whose mutation is permissive for metaplastic polyp formation exists, it is highly unlikely to be involved in colonic carcinogenesis.

The one aspect of the finding of a high frequency of $\mathrm{K}$-ras mutations in metaplastic polyps that could have a bearing on clinical practice is its implication for colorectal cancer screening by the detection of mutant K-ras in faecal samples. As methods are refined to improve the sensitivity of this technology, it is conceivable that shedding of mutant bearing cells from metaplastic polyps (and indeed from ACFs) will result in an increased frequency of false positive results. Only time will tell whether this theoretical dilemma becomes realised, but it does illustrate the importance of understanding the molecular basis of all pathological lesions, no matter how apparently insignificant at first sight, for meaningful clinical practice. Metaplastic polyps, the Cinderellas of colorectal pathology, may still get a look in at the Ball!

GERAINT T WILLIAMS

Department of Pathology,

University of Wales College of Medicine,

Heath Park, Cardiff CF 4 XN

1 Jass JR, Young PJ, Robinson EM. Predictors of presence, multiplicity, size and dysplasia of colorectal adenomas: a necropsy study in New Zealand. Gut 1992; 33: 1508-14.

2 Cappell MS, Forde KA. Spacial clustering of multiple hyperplastic, adenomatous and malignant colonic polyps in individual patients. Dis Colon Rectum 1989; 32: 641-52.

3 Morson BC, Dawson IMP, Day DW, Jass JR, Price AB, Williams GT. Morson $\mathcal{E}$ Dawson's Gastrointestinal pathology. 3rd edn. Oxford: Blackwell Morson $\mathcal{E}$ Daws

4 Hanby AM, Poulsom R, Singh S, Jankowski J, Hopwood D, Elia G, et al. Hyperplastic polyps: a cell lineage which both synthesizes and secrete refoil-peptides and has phenotypic similarity with the ulcer-associated cell lineage. Am ₹ Pathol 1993; 142: 663-8.

5 Longacre TA, Fenoglio-Preiser CM. Mixed hyperplastic adenomatous polyps/serrated adenomas: a distinct form of colorectal neoplasia. $A m \mathscr{f}$ Surg Pathol 1990; 14: 527-37.

6 Bardi G, Pandis N, Fenger C, Kronborg O, Bomme L, Heim S. Deletion of $1 \mathrm{p} 36$ as a primary chromosomal aberration in intestinal tumorigenesis. Cancer Res 1993; 53: 1895-8.

7 Lothe RA, Andersen SN, Hofstad B, Meling GI, Peltomaki P, Heim S, et al. Deletion of $1 \mathrm{p}$ loci and microsatellite instability in colorectal polyps. Genes Chromosom Cancer 1995; 14: 182-8.

8 Jeevaratnam P, Cottier DS, Browett PJ, Vandewater NS, Pokos V, Jass JR. Familial giant hyperplastic polyposis predisposing to colorectal cancer Familial giant hyperplastic polyposis predisposing to colorectal cancel

9 Jen J, Powell SM, Papadopoulos N, Smith KJ, Hamilton SR, Vogelstein B, et al. Molecular determinants of dysplasia in colorectal lesions. Cancer Res et al. Molecular de

10 Shpitz B, Hay K, Medline A, Bruce WR, Bull SB, Gallinger S, et al. Natural history of aberrant crypt foci - a surgical approach. Dis Colon Rectum 1996; 39: 763-7.

11 Polyak K, Hamilton SR, Vogelstein B, Kinzler KW. Early alteration of cellcycle-regulated gene-expression in colorectal neoplasia. Am $\mathcal{F}$ Pathol 1996 149: $381-7$.

12 Williams GT. Metaplastic polyposis. In: Phillips RKS, Spigelman AD, Thomson JPS, eds. Familial adenomatous polyposis and other polyposis syndromes. London: Edward Arnold, 1994: 174-87.

13 Rex DK, Cummings OW, Helper DJ, Nowak TV, McGill JM, Chiao GZ, et al. 5-year incidence of adenomas after negative colonoscopy in et al. 5-year incidence of adenomas after negative colonoscopy in 